\title{
The Related Interest Game in Ecological Construction of Farmers' Tea Plantation
}

\author{
Gao Shuilian \\ College of Economics, Fujian Agriculture and Forestry \\ University \\ Tea Science of Anxi College, Fujian Agriculture and \\ Forestry University \\ Fuzhou, Fujian 350002, China \\ gaoshuilian@126.com
}

\author{
Yang Jiangfan* \\ College of Economics, Fujian Agriculture and Forestry \\ University \\ Collaborative Innovation Center of Chinese Oolong Tea \\ Industry \\ Fuzhou, Fujian 350002, China \\ yjf3001@163.com
}

\begin{abstract}
To elucidate complicated interest relations of ecological construction in the tea plantation and solve the problem of slow ecological construction of farmers' tea plantation, this paper analyzes the real problem of ecological tea plantation model and the interest relationship by field investigation and literature research. The results show that there are so many interest games in the ecological construction of farmers' tea plantation, such as uncoordinated interest contradictions between the long and short term, unbalance mental state because of the feeling of differences between gain and loss, facilitating the welfare of others, and so on. Therefore, it is suggested that some measures for coordination the interests is necessary. For example, we can set the basic standard of ecological tea plantation and accelerate the acknowledgement of the forest right in the tea garden, we also can optimize the economic structure of ecological tea plantation at the same time, can promote the ecological construction by leaguing the tea garden. This paper makes a new exploration on the related interests of ecological construction of the farmers' tea plantation and its coordination measures.
\end{abstract}

Keywords-farmers; tea plantation; ecological construction; interest game; coordination mechanism

\section{INTRODUCTION}

Tea tree[Camellia sinensis (L.) O. Ktze.] is a perennial woody plant, and it had been belonged to an economic and ecological forest by Chinese Forestry Bureau in 2001(Forest Retreat [2001] 550). The ecological tea plantation is similar to the forest. It has the functions of regulating the climate, conserving the water, keeping the soil and water, keeping the soil and sand, improving the soil and reducing the pollution. However, if the management is not fit, the greenhouse gas emissions of the tea plantation will be higher than other cultivated land. Furthermore, unreasonable management will generate soil serious erosion and the deteriorated soil environment. As of 2016, the area of tea plantation in the world is more than 4.7 million hectares. The area of Chinese tea plantation is about $60 \%$ all of it and the tea farmers are more than 80 million. From the tea plantation and the safety of tea quality of tea to increase income of farmers, tea plantation has become the focus of key areas of agriculture. Since the beginning of the 21 st century, most of the tea area attaches great importance to the ecological construction of tea plantation, and the introduction of relevant policies and incentives achieved better results, however, more than $80 \%$ of the tea plantation has been owned by small farmers in China and the ecological construction of tea plantation involved in complex interests relationship, which may be an important reason for the slow ecological construction of farmers' tea plantation. Li Weiyan (2015), Zheng Longzhang (2009), Lin Aihui (2014) and others have studied the influencing factors of tea farmers' ecological construction decision-making [1-3]. But interest coordination research is relatively less, which cannot provide a reference for elucidate these relations.

\section{REALISTIC PROBLEMS OF ECOLOGICAL TEA PLANTATION MODEL}

The ecological tea plantation is the result of ecological construction of tea plantation, and ecological tea plantation is an ecological system that is complex and artificial. We need sort out the reality of the problem in the ecological tea plantation model before analysis relevant interest relation of ecological construction in tea plantation.

\section{A. The chaos of reality}

Ecology is the living state of biology, which refers to the creatures' relationship and the relation between biology and their environment, it also refers to the biological nature and life habits of the organisms. It originated from a neutral word, and after continuous derivation, "ecological" has been used to indicate healthy, beautiful and harmonious things. Therefore, it become a so prevalent word that a lot of things are vested with "ecological", such as, the ecological province, ecological cultural, ecological enterprises, even the ecological fish, ecological eggs, etc. Ecological tea plantation has been widely used in the tea industry, but the people has its own words and different opinions. Some media propaganda "ten thousand mu of ecological tea plantation(field)", "ecological tea plantation(field)", in fact, which is really a nice surrounding ecological environment around tea plantation, some trees are 
left on the side of the tea plantation or the place where the tea plantation cannot be cultivated. Or the tea tree is taller, and the sealing line is thickly arranged, there are good vegetation coverage; Or intercropping a few fruit trees or other trees in the tea plantation; Even some are ordinary pure tea plantation, only are at the high altitude and so on. They do not meet the characteristic and standard of ecological tea plantations. The author input "ecological tea plantation" in the web of Baidu to search images and find that the "ecological tea plantations" are all kinds of forms. They can be roughly divided into seven tea plantations in the randomly intercepted 11 images (figure 1), such as tea plantations: (1) near the mountain and by the river, (2)near forest, (3) (5) (10)pure tea plantation in mountains, (4)mistshrouded in mountains, (6) intercropped a few trees as protection zone, (7) (11) pure tea plantation on ground, (8) (9) interplant with tree or fruit tree as compound cultivation. Most of them don't meet the criteria of ecological tea plantation.

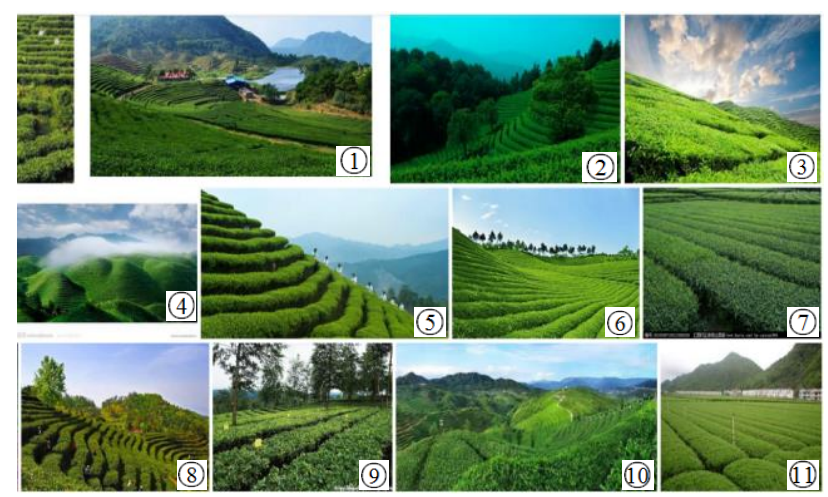

Fig. 1. Baidu image of "ecological tea plantation" from the web of https://image.baidu.com/search/index?tn

\section{B. Diversity of patterns}

The existing ecological tea plantation can be mainly divide into natural ecological tea plantation and artificial ecological tea plantation. Among them, the natural ecological tea plantation is refers to tea plantation with partly exploitation in the region that good ecological environment, which is suitable for the opening of the tea plantation, according to local conditions, the tea plantation area is often not more than $40 \%$ in square. The quantity of this kind of tea plantation is very limited because it must have good natural condition and ecological development technology. The main pattern of ecological tea plantation is artificial compound ecological tea plantation, It is a highly efficient artificial agroecosystem which follows the ecological principles and based on tea tree as the main species. This ecological tea plantation model can further be divided into three patterns. They are stereoscopic structure pattern, food chain pattern, stereoscopic structure mixed with food chain. The stereoscopic structure pattern is a multi-species compound pattern, includes compound pattern of tea $\&$ forest (Figure 2), tea $\&$ fruit, tea $\&$ flower, tea $\&$ herb, tea $\&$ green manure, tea $\&$ herbage, tea $\&$ mulberry, tea $\&$ plastic. The food chain pattern is tea - poultry (animal husbandry) compound pattern. The stereoscopic structure mixed with food chain pattern includes tea - livestock - grass, forest - tea - animal husbandry (poultry) - marsh, tea herb(herbage) - poultry (livestock) - fishing - marsh. A total of 13 types in the three patterns [4]. If further take subdivision, and biodiversity and management took into account, the ecological tea plantation model is far more than these.

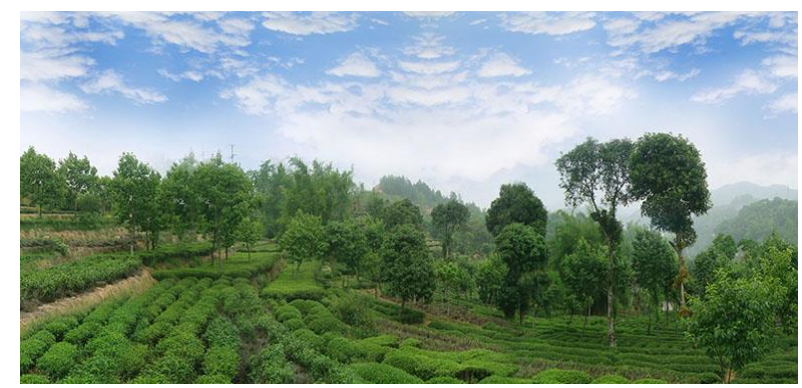

Fig. 2.Tea - forest compound cultivation from the web of Fujian Bama Tea Co.

\section{Difficulty of choice}

The construction of ecological tea plantation also has the following difficulties: (1) Local topography, soil, climate, water resources, original vegetation and other natural conditions are different. Once something changed, such as different mountain, different river, different orientation, these conditions may have great differences. (2) If the local tea variety is different, ecological adaptability is not the same. For example, according to the majority of respondents reflect that the Tieguanyin Olong tea variety does not fitted the dense shade. Once dense shaded, the production tea will be low, and its aroma and taste will thinning. (3) The ecological model variety and the collocation of green plants are difficult, there is no standard of shading, kind of tree specie and green manure, so it is difficult to set up. And the adaptability of plants are different, in a place where is no growth, whereas it may too growth to control and turn into disaster in the other a place because there is no natural enemies. (4) Farmers lack of ecological tea plantation construction experience and technology. The construction of ecological tea plantation cultivation take years, even decades, and it unlike the number of tea process experience can be accumulated every day in seasonal time. Therefore, few rounds of ecological tea plantation construction experience can be accumulated in one people's life. (5) The cost of trial and error is very high. Once is the tree chosen wrong, the tree will be dug and planted again. Because the tree has a longer growth period and the cost of seedling and planting management is relatively high, the time cost and the direct cost are relatively large. These problems will cause most farmers to consider whether or not to carry out ecological construction and what ecological patterns should be adopted. It is difficult to make decisions and choose. Therefore, in the end, many tea farmers have chosen to maintain the pure tea plantation or wait other people's ecological construction. 


\section{THE GAME OF INTERESTS RELATED IN THE ECOLOGICAL CONSTRUCTION OF TEA PLANTATION}

Ecological tea plantation is a complex ecosystem accord with the artificial construction, which involves interests of short-term and long-term, gains and loss and the relationship in or between groups. The coordination is difficult. There are game within and among the interests owners.

\section{A. Long - term and short - term interests are difficult to co- ordinate}

Eco-build took for human sustainable development, which must take into account the synergetic benefit between shortterm and long-term. It is to meet the needs of contemporary people, at the same time, does not constitute harm to the needs of future generations. The ecological construction of tea plantation plays the most important basic role in the sustainable development of tea industry. In the short term, the ecological investment of tea plantation is huge and the income is small. However, in the long term, the climate of tea plantation is improved obviously, the lighting conditions are optimized, the humidity of tea plantation is increased, and the soil loss is much less, at the same time, the soil physical and chemical properties are improved and the need of fertilizer can be decreased. It can reduce the tea pests and diseases, and then the input of pesticide become less, the tea quality in the park will be improved. Therefore, the ecological construction of tea plantation has more long-term interests. However, most of the tea farmers can't cope with the ecological construction of tea plantation, objectively because for the food, schooling, disease medical treatment, house and other economic reasons, subjectively because of the weak ecological awareness, the absent concept of sustainable development. Which lead to more urgency in the current interests and short-term benefits. It's said that "two birds in the forest inferior to a bird in the hand". It is difficult to coordinate the relationship of long-term interests and short-term interests. Therefore, it seriously hinders the progress of tea plantation ecological construction.

\section{B. The different feeling between gain and loss is great}

There are more research about gain and loss of mental feeling in psychology and economics, which found at least two aspects. One is that the pain of loss is greater than the happiness of benefit in a same value substance; On the other hand, with the change of reference point, the difference of people feel about gain and loss also changed. A study by Daniel Kahneman, a Nobel prize-winning economist, found that the happiness brought by picking up $\$ 100$ was less than the pain by loss of $\$ 100$ [5]. This sense of gain and loss also impedes the ecological construction of tea plantation. Is mainly manifested in two aspects: on the one hand, although after the ecological construction, for some tea tree that did not directly shaded, the average yield can increase by more than $10 \%$, and fresh leaf quality will be improved, but the tree need occupy about $10 \%$ of the original tea garden land, furthermore, the output of fresh tea leaves which under the density canopy may be decreased more than $40 \%$, the quality of Oolong tea will also decline, and the gain of yield and quality are less hen loss in the per unit area. So the feel contrast in the mind is great, and often neglected incremental yield and quality of tea plantation area is far greater than the reduction of the tea plantation area in fact. On the other hand, before ecological construction, everyone's tea garden is pure tea plantation, tea production and quality is almost the same, and farmers' mental is also balanced. Now the yield and quality of tea have been reduced, although only a small part of the tea tree, whether it is compared with their own tree next to the tea (Reference point 1) or compared with the surrounding pure tea plantation (Reference point 2), it has a big gap in farmers' mental. Li Weiyan (2015) found the reasons for their reluctance to support the construction of ecological tea plantation, they worried that the reduction of tea plantation area and the influence of the economy accounted for 46.81 percent and 36.17 percent of respectively [1].

\section{The psychological displeasure of facilitating others' welfare by self-built ecological construction}

There are three kinds of theories of farmers' activities overseas. Whether the "rational farmer said" that to make a reasonable choice for pursuing the biggest benefit of output, or "farmers' irrational behavior said" that pursuing of cost minimization, not "subsistence small-scale peasant said" that simply the pursuit of survival and satisfy consumer but not the maximum profit [6], most of them agree that farmers behavior is selfish. Tea farmers belong to the scope of small farmers. There are some people who are helpful and have public mind in reality, but most people in the ecological construction of tea plantation are in line with the doctrine behavior and psychological reaction mentioned above. For the tea farmers who construct ecological tea plantation, their inputs will increase, but their income increased far less than the increase in investment, at the same time, their behavior will optimize the temperature, light, water, gas, and other environmental conditions of the nearby tea plantation, so that the nearby tea plantation gets fresh air, more humidity and diffuse light increase. If the number is enough, they can improve the nearby tea yield and quality, thus make additional benefit for nearby. This is the said the "our trees give others shade", it will make a psychological unpleasant feeling for tea farmers who construct the ecological tea plantation, which will hinder they ecological decision-making.

\section{SUGGESTIONS ON COORDINATION MEASURES OF ECOLOGICAL INTERESTS IN TEA PLANTATION}

The problems of ecological tea plantation construction model and the three contradictions of the interests of ecological construction in tea plantation can be solved or mitigated by the following measures.

\section{A. Set the basic standard of ecological tea plantation}

The reality problems of the ecological model of tea plantation cause that the ordinary tea farmers have no idea in the ecological construction of the tea garden or blindly follow the way of others, which lead to the bad construction effect, in turn, affects the construction of confidence and motivation. The reason is that there is no uniform standard in the ecological tea plantation at present. Although the ecological 
construction of tea plantation should be adapted to local conditions, especially the matching species and their planting methods, density are constrained by the geographical location, climate and environment. We can guide the construction through the target by some basic standards, for example, green plant coverage, bio-rich, soil physical and chemical indicators, water quality and water storage, air quality and other indicators. In addition, the major tea areas should strengthen the research of appropriate model of tea plantation ecological construction, and establish system including trees, grass, green manure, fertilizer, water, roads and related construction and management methods, for local tea farmers to select, and then improve construction efficiency and benefit.

\section{B. Accelerate the acknowledgement of tea plantation's forest right}

In addition of subjective reasons, unclear property rights of tea plantation play a pivotal role in the problem that tea farmers generally pursue short-term interests. The investment of tea plantation ecological construction is big, but its effect is slow, and unclear property rights will make against long investment scale. According to the spirit of reform of forest rights in the new period, some areas have already realized the right of tea plantation and issued forest warrants for tea plantation. Awarded property rights, the tea plantation can be inherited and traded, and it also can be used as loan mortgage. Thus tea plantation will become a "green bank", and further improve the tea farmers' confidence and the autonomy of building behavior. For promoting the general construction of ecological tea plantation, it is suggested to speed up the confirmation and certification of the tea plantation rights, including the trees in the park, which will help ensure the long-term benefits of ecological construction of tea farmers so as to promote the construction of ecological tea plantations.

\section{Optimize the economic structure of ecological tea plantation}

For tea farmers in the ecological tea plantation construction, the feeling of gain is not obvious, but the feeling of loss is very obvious, and the lopsided psychological feelings can be made up by increasing the total income. An effective way is guiding farmers to interplant valuable trees or high economic value of tree species in and around the tea plantation that adapted to the local natural conditions, by strengthening the public research and expert advice. Furthermore, encourage people to interplant local soybeans, peanuts or suitable herbal and other economic crops or herbs in tea plantation. All of these measures not only can improve the ecological conditions of tea garden, but also increase comprehensive economic income of tea plantations. When the additional income is significantly greater than the loss, it is easy to produce psychological satisfaction and voluntary investment in ecological tea plantation construction.

\section{Promote the ecological construction by leaguing the tea garden}

Tea farmers who build their own ecological tea plantation cannot be fully profitable, and the surrounding tea plantation has been the benefits. This is mainly due to the small and scattered tea plantation owned by tea farmers. According to the survey of Anxi County tea farmers in 2012 - 2013 , which shows that a family owned tea plantation average of only 0.45 hectares, and distributed in 6.32 places mixed with nearby tea garden [3]. To solve the psychological imbalance and the problem of dispersed tea plantation is to encourage the tea garden circulation or establish a unified tea plantation base unified management of close co-operatives and to promote the unified tea plantation ecological construction and management. Therefore, the externalization can be solved in a tea garden to overcome the external characteristic and increase the enthusiasm of ecological construction in tea plantation.

\section{THE RESEARCH CONCLUSION}

The results show that: (1) Ecological tea plantation has not formed a unified basic standard because of natural conditions, biological growth habits, farmer's own factors and the initial stage of the academic research. The model is diverse and difficult to choose, so that it is difficult to build ecological tea plantation for small farmers. (2) In the ecological construction of tea plantation, the farmers have complex interest contradictions, such as the benefits of long-term and shortterm, gain and loss, one and others. (3) For solving the problem of ecological tea plantation model and coordinating the complex relationship in or between the owners, we can set the basic standard of the ecological tea plantation, and clarify the property rights of the tea plantation and its trees, at the same time, optimize the economic structure of the ecological tea plantation, and promote the ecological construction by leaguing the tea garden. Through the measures, we also can increase the tea farmers' income and improve the enthusiasm of farmers' tea plantation ecological construction, so as to promote the ecological construction of tea plantation.

\section{ACKNOWLEDGMENT}

Gao Shuilian (1979.9-), male, doctoral student, associate professor, research direction for the tea industry economic management, tea tree nutrition and tea plantation ecology; * Corresponding author : yjf3001@163.com.

The major projects of research database of Science and Technology Association in Fujian Province. (No.FJKXZD1501).

Science and technology plan project of QuanZhou City. (No. 2016N032)

\section{REFERENCES}

[1] Li Weiyan, Sun Tao, Zhou, et al. Study on the influencing factors of ecological tea plantation construction [J]. Journal of Anhui Agricultural Sciences, 2015, 43 (15): 322-323.

[2] Zheng Longzhang. Tea farmers use pesticide behavior factors - Taking Fujian Province as an example [D]. Fuzhou: Fujian Agriculture and Forestry University, 2009.6.

[3] Lin Ahui, Gao Shui Lian, Ye Naixing. An Empirical Study on the Factors Affecting the Construction of Tea Farmers' Ecological Tea Plantation - Taking Anxi County as an Example [J]. Tea Science and Technology, 2014, (3): 54-60.

[4] Yu Wenquan, Zhang Cuixiang. Ecological tea plantation research progress and thinking [J]. Chinese tea, 2009, (10): $10-13$. 
[5] Xin Xin Ran. The psychological effects of the loss [J]. Prosecution situation, 2015, (16): 42-43.

[6] Zhang Sasha. Review of Farmers' Ecological Behavior Research [J]. Mass Commerce, 2010, (3): 7-8. 